\title{
THE PROGNOSTIC VALUE OF FLASH VISUAL EVOKED POTENTIALS IN THE ASSESSMENT OF NON-OCULAR VISUAL IMPAIRMENT IN INFANCY
}

\author{
M. P. CLARKE ${ }^{1}$, K. W. MITCHELL ${ }^{2}$ and M. GIBSON ${ }^{3}$ \\ Newcastle upon Tyne
}

\begin{abstract}
SUMMARY
The results of flash visual evoked potentials (VEPs) in 44 infants blind or severely visually impaired from nonocular causes are presented, and related to the subsequent visual outcome. Ocular causes of visual impairment were excluded by clinical examination and electroretinography. Using a $2 \times 2$ contingency table, a significant association between VEP and outcome was demonstrated $\left(\chi^{2}=3.51,1\right.$ d.f., $\left.p=0.05\right)$. Of 13 infants with normal VEPs, 11 demonstrated substantial visual improvement (negative predictive value $=84.6 \%$ ). However, of the 31 with abnormal VEPs, only 14 remained severely impaired/blind; the other 17 demonstrating visual improvement $($ positive predictive value $=$ $45.1 \%$ ). The sensitivity of the method was high in that 14 of $16(87.5 \%)$ infants who remained impaired/blind had abnormal VEPs, but specificity was low as only 11 of $28(39.3 \%)$ who showed visual improvement had normal VEPs. The accuracy of the technique was therefore low, 25 of $44(56.8 \%)$ being true positive/ negative. With regard to visual outcome when faced with an apparently blind infant, it is important not to be too pessimistic for, as is shown in this study, 28 of 44 demonstrated substantial improvement. There are no absolute indicators of prognosis, but the presence of structural cerebral lesions and a history of either neonatal meningitis or encephalopathy are relatively bad prognostic signs. The flash VEP, despite its limitations, is a useful prognostic tool, particularly in those apparently blind infants whose normal ocular examination/electroretinogram is accompanied by normal VEPs. Those with abnormal VEPs, however, do not necessarily have a poor prognosis, but should be followed-up as maturational changes and/or improvements in function of the sensory pathway will be reflected in the evoked potentials.
\end{abstract}

From: ${ }^{1}$ Department of Ophthalmology, ${ }^{2}$ Regional Department of Medical Physics and ${ }^{3}$ Department of Child Health, Royal Victoria Infirmary, Newcastle upon Tyne, UK.

Correspondence to: Michael Clarke, Department of Ophthalmology, Royal Victoria Infirmary, Newcastle upon Tyne NE1 4LP, UK.
The management of the apparently blind infant is a frequent and challenging problem in paediatric ophthalmology. The differential diagnosis includes structural ocular lesions such as cataract; retinal dystrophies (in which there may be no visible retinal abnormality at presentation); visual pathway lesions, such as optic nerve hypoplasia and porencephalic cysts; and delayed visual maturation. Rarely, ocular movement disorders such as congenital oculomotor apraxia may simulate sensory deficits.

Clinical assessment consists initially of the history, with particular reference to the pregnancy, perinatal period and familial eye disorders. Clinical examination and electroretinography will rule out ocular disorders, ${ }^{1}$ but problems of the sensory and higher visual pathways can only be investigated by preferential looking (PL) or visual evoked potential (VEP) methods. ${ }^{2}$ As the former can result in very arbitrary outcomes in children with severe cortical visual impairment (CVI), the latter method has, of necessity, been the only method available. As in several centres, it has been the authors' practice to supplement clinical assessment and electroretinography with a VEP investigation, in the belief that this contributes both diagnostic and prognostic information. The view has been supported in studies on $\mathrm{CVI}_{2}^{3-5}$ occipital lobe anomalies, ${ }^{6}$ perinatal asphyxia $^{7-9}$ and delayed visual maturation (DVM).${ }^{10,11}$ However, it is contested in studies of children who suffered hypoxic insults, ${ }^{12}$ children with CVI as compared with those with neurological handicap and normal vision ${ }^{13}$ and CVI alone, ${ }^{14}$ which found VEPs of little value. Indeed, flash VEPs have been elicited in children blind from occipital cortex lesions, ${ }^{13,15,16}$ or, indeed, absence of occipital cortex. ${ }^{17}$ This has led to the suggestion that such VEPs may be generated, at least in part, by subcortical or extrageniculate sources. In addition, neonatal VEPs demonstrate significant maturational changes in the first 6 months of life, ${ }^{3,18}$ making interpretation difficult. Given these difficulties, it is

Eye (1997) 11, 398-402 을 1997 Royal College of Ophthalmologists 
not surprising that the value of VEPs as a diagnostic and prognostic tool in these infants is controversial.

This study presents VEP data obtained at presentation of 44 apparently blind infants between 1991 and 1994, and attempts to define their prognostic value as judged by subsequent clinical follow-up.

\section{PATIENTS AND METHODS}

The infants were all from the Northern Region of England and were referred to and seen by one ophthalmologist (M.C.) because of a lack of visual response. Children with ocular disorders demonstrated by clinical examination or electroretinography have been excluded.

Visual response was assessed by a preferential looking technique (Keeler cards), fixation behaviour, or response to a light source, and classified as shown in Measurements of Vision below. Visual responses were severely impaired or absent in all infants on presentation. Responses at outcome are detailed in Tables III-VI. The infants had evoked potential testing in the same laboratory under standard conditions (see below). Children with CVI were followed in a joint clinic by an ophthalmologist (M.C.) and a paediatrician (M.G.).

The causes of visual loss, which were usually not apparent at first assessment, are shown in Table I.

\section{VEP Technique}

Binocular VEPs were elicited using a Ganzfeld bowl stimulator, the strength of a stimulus being 1 Standard Flash and proportionate photopic background illumination (ISCEV 94). The child was sat or supported on the mother's knee and held with its head in the aperture of the Ganzfeld bowl. The eyes were open in all investigations and the children were

Table I. Underlying diagnoses

1. Structural cerebral anomalies $(n=12)$

Porencephalic cysts $(n=3)$ (Fig. 1)

In utero cerebral infarcts $(n=3)$

Septo-optic dysplasia/optic nerve hypoplasia $(n=3)$

Microcephaly $(n=2)$

Chiasmal glioma $(n=1)$

2. Delayed visual maturation $(n=10)$

Type 1 (pure) $(n=6)$

Type $2(+$ developmental delay $)(n=1)$

Type 3 (+ ocular anomaly) $(n=3)$

3. Neonatal encephalopathy $(n=6)$

4. Meningitis \pm hydrocephalus $(n=5)$

5. Associated with specific syndromes $(n=5)$

Chromosomal abnormalities $(n=3)$

Hallerman Streiff $(n=1)$

Undiagnosed dysmorphic syndrome $(n=1)$

6. Neonatal epilepsy, ? cause $(n=3)$

7. Premature/intraventricular haemorrhage \pm hydrocephalus $(n=2)$

8. Premature, opiate toxicity $(n=1)$

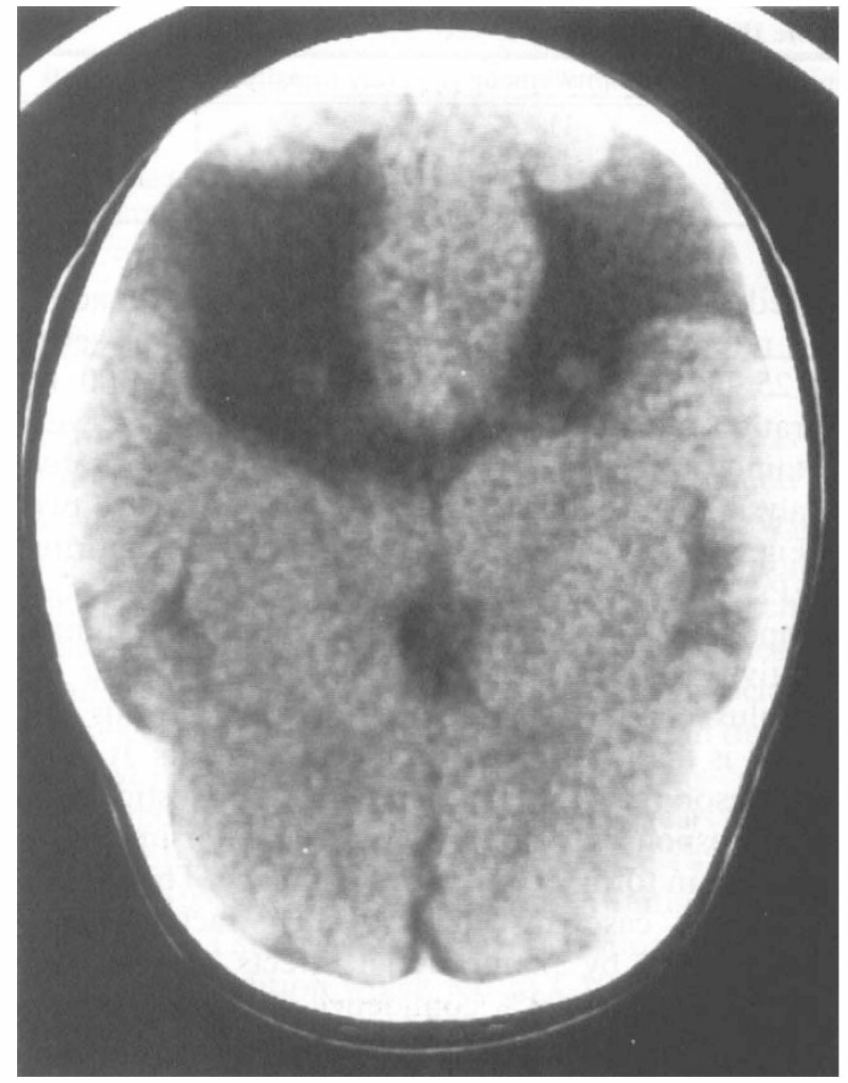

Fig. 1. Porencephalic cysts. VEP delayed and attenuated. Child remained severely visually impaired.

unsedated. The stimulus repetition rate was set to 1 per second. Silver/silver chloride disc electrodes were attached to the scalp in the following positions: ${ }^{19}$ active, Oz; reference, Cz; earth, Pz. Electrode

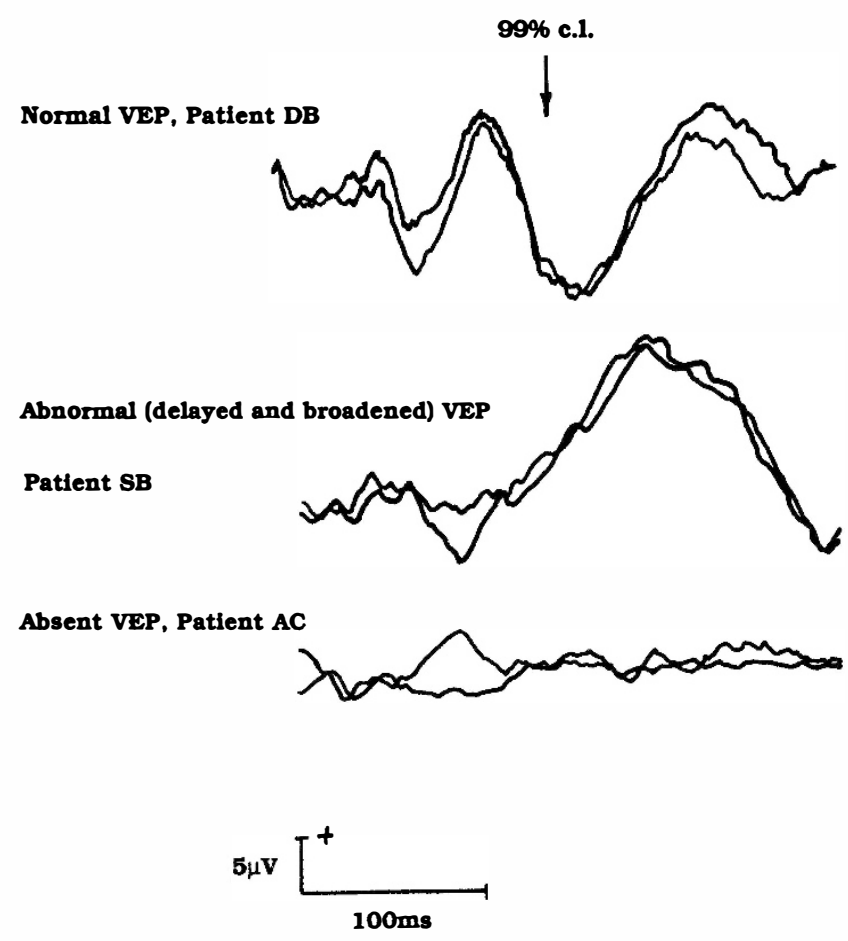

Fig. 2. Examples of normal and abnormal visual evoked potentials (VEPs) 
Table II. Visual outcome

\begin{tabular}{|c|c|c|c|}
\hline$\overline{\text { Initial VEP }}$ & Improvement & Severely impaired/blind & Totals \\
\hline Normal & 11 & 2 & 13 \\
\hline $\begin{array}{l}\text { Aonormal } \\
\text { Totals }\end{array}$ & 28 & $\begin{array}{l}14 \\
16\end{array}$ & $\begin{array}{l}31 \\
44\end{array}$ \\
\hline
\end{tabular}

impedances were adjusted to be $<2 \mathrm{k} \Omega$ in both active and reference leads, amplifier bandwidth was set to $1-125 \mathrm{~Hz}$, and averages of 64 epochs of $300 \mathrm{~ms}$ duration acquired. At least two averages were obtained to check for consistency, and quantitative analysis was performed on the average of these two.

Fig. 2 shows examples of normal and abnormal VEPs. The normal response demonstrates the main components of the flash VEP ${ }^{20}$ but the dominant positivity $\left(\mathrm{P}_{\mathrm{IV}}\right)$, occurring at $105-125 \mathrm{~ms}$ under the stimulus conditions used for children of this age group, is the most robust of all components. It is for this reason that it was measured in all investigations. Flash responses demonstrate large inter-individual variation in form, amplitude and latency. This is even more the case in infancy, such factors being compounded by maturational effects - hence the prolonged upper $99 \%$ confidence limit of normality for $\mathrm{P}_{\mathrm{IV}}$ latency $(145.0 \mathrm{~ms})$ as indicated in Fig. 2 (these data are derived from our control database of 32 infants, age range 5-20 months, mean latency 115.5 $\mathrm{ms}, \mathrm{SD} 13.6 \mathrm{~ms})$. The first of the two abnormal traces shows a significantly delayed and broadened $\mathrm{P}_{\mathrm{IV}}$ of latency 190-200 ms. Gross sensory retinocortical function can therefore be regarded as present, but significantly impaired. In the second, no consistent EP activity over and above background noise can be distinguished. It can therefore be concluded that pathway function is grossly impaired - if not obliterated - in this case. VEP abnormality was therefore based on the observation of delay or significant attenuation $(<5 \mu \mathrm{V})$ or absence of a response (with or without concomitant delay).

\section{Measurement of Vision}

The visual response at the latest follow-up visit was classified as:

Normal for age: Response to Keeler cards within normal limits or $6 / 6$ on letter or picture matching.
Impaired for age: Response to Keeler cards below normal limits or $<6 / 6$ on letter or picture matching or fixation and following.

Severely impaired: Response to light only.

Blind: No detectable visual response.

All infants were blind or severely visually impaired on presentation, and those who were impaired or normal at outcome were judged to have improved.

\section{RESULTS}

The relationship of the VEP obtained at presentation in all 44 infants with the final visual outcome is expressed in the form of a $2 \times 2$ contingency table (Table II). 'Improvement' included not only those who demonstrated such, but also those whose vision normalised. Testing for significance using chi-square $\left(\chi^{2}\right)$ demonstrated that the association between initial VEP and visual outcome was just significant $\left(\chi^{2}=3.51\right.$, 1 d.f., $p=0.05$ ). The method was shown to have high negative predictive value $(84.6 \%)$ as 11 of 13 infants with normal VEPs demonstrated substantial visual improvement. However, it showed low positive predictive value $(45.1 \%)$ as 14 of the 31 infants with abnormal VEPs remained severely impaired/blind, the other 17 demonstrating visual improvement. Sensitivity of the method was high in that 14 of $16(87.5 \%)$ infants who remained impaired/blind had abnormal VEPs, but specificity was low, only 11 of $28(39.3 \%)$ infants who showed visual improvement having normal VEPs. Accuracy was therefore low at $56.8 \%$ ( 25 of 44 , true positive and true negative).

Tables III-VI show the VEP findings for the major diagnostic categories. In total, 28 of the cohort (63.6\%) demonstrated substantial visual improvement.

\section{DISCUSSION}

This study indicates that there is a significant, albeit marginal, association between the flash VEP and visual outcome in a cohort of children with various forms of CVI. It confirms the view that such children who have a normal VEP on presentation will, in general, have a good prognosis for visual improvement, if not normalisation. This finding accords with that reported in perinatal asphyxia, ${ }^{9}$ acute cortical

Table III. Infants with cerebral malformations $(n=12)$

\begin{tabular}{|c|c|c|c|}
\hline Type of visual malformation & $n$ & Initial VEP findings & Outcome \\
\hline Optic nerve hypoplasia/septo-optic dysplasia & 3 & $\begin{array}{l}2 \text { Delayed } \\
1 \text { Absent }\end{array}$ & $\begin{array}{l}\text { Severely impaired } \\
\text { Blind }\end{array}$ \\
\hline Porencephalic cyst & 3 & 2 Delayed and attenuated & $\begin{array}{l}\text { Blind } \\
\text { Homonymous hemianopia }\end{array}$ \\
\hline In utero cerebral infarct & 3 & $\begin{array}{l}1 \text { Absent } \\
1 \text { Normal } \\
1 \text { Delayed } \\
1 \text { Absent }\end{array}$ & $\begin{array}{l}\text { Blind } \\
\text { Impaired } \\
\text { Severely impaired } \\
\text { Blind }\end{array}$ \\
\hline Microcephaly & 2 & $\begin{array}{l}1 \text { Delayed } \\
1 \text { Absent }\end{array}$ & $\begin{array}{l}\text { Severely impaired } \\
\text { Impaired }\end{array}$ \\
\hline Chiasmal glioma & 1 & 1 Absent & Blind \\
\hline
\end{tabular}


Table IV. Infants with delayed visual maturation $(n=10)$

\begin{tabular}{llll}
\hline Type of DVM & $n$ & Initial VEP findings & Visual outcome \\
\hline Pure & 6 & 3 Normal & Normal \\
& & 1 Absent & Normal \\
& & 2 Delayed & Normal \\
+Developmental delay & 1 & 1 Delayed & Impaired \\
+Ocular anomaly & 1 & 1 Delayed & Impaired \\
Ocular albinism & 1 & 1 Delayed & Impaired \\
Anterior polar cataract + developmental delay & 1 & 1 Normal & Benign congenital motor nystagmus \\
\hline
\end{tabular}

blindness $^{4}$ and idiopathic DVM. ${ }^{10}$ The study of Wong, ${ }^{5}$ however, disputes this position, as in a series of 23 cases of acquired cortical blindness, of the 6 patients with normal flash VEPs only 2 had a good outcome.

The finding of a normal flash VEP does not allow the conclusion that the visual pathway is functioning normally. Bodis-Wollner et al..$^{15}$ described the finding of normal flash VEPs in a blind child with destruction of visual association areas 18 and 19 but preserved primary visual cortex (area 17). Frank and Torres ${ }^{13}$ found no difference in the VEPs of 30 'cortically blind' neurologically impaired children, compared with 31 children with central nervous system disease but without visual symptoms. Whiting et al. ${ }^{16}$ studied 23 children with cortical visual impairment using VEPs and visual evoked potential mapping (VEPM), and found the diagnosis of CVI confirmed only in 10 by VEPs, but in all 23 by VEPM.

Evidence for the existence of extrageniculostriate visual systems has come from animal experiments, ${ }^{21}$ and dysfunction of this system has been postulated as the cause of DVM. ${ }^{11}$ Indeed, it is suggested that in the normal infant both behavioural and electrophysiological aspects of visual function may be mediated subcortically in the first 2-3 months of life. ${ }^{17}$ Severe cortical impairment might therefore not be detected by the VEP.

It is also important to recognise that flash VEP components measured in this study were those that principally relate to sensory processes, i.e. they occurred within $\sim 200 \mathrm{~ms}$ of the stimulus. It is thus reasonable to speculate that higher visual association areas, which contribute to later electrophysiological activity, i.e. $200-500 \mathrm{~ms}$, make little contribution to this activity. The significant role these centres play in cognitive functioning of a developed visual system suggests that pathological influences specific to them, in the presence of normally functioning primary visual cortex and its associated retinocortical con-

Table V. Infants with meningitis $(n=5)$

\begin{tabular}{ll}
\hline Initial VEP findings & Visual outcome \\
\hline 3 Delayed & 1 Normal \\
& 1 Impaired \\
& 1 Severely impaired \\
1 Attenuated & Severely impaired \\
1 Attenuated and delayed & Normal \\
\hline
\end{tabular}

nections, may be unheralded by the VEP. There is no doubt that in some forms of CVI this will indeed be the case, and in 'non-pathological' forms of visual impairment such as idiopathic DVM it is certainly plausible to suggest that a patent sensory visual chain - and its attendant normal VEPs - will exist despite poorly developed functioning of visual association centres. ${ }^{10,15}$ This was presumably the case in our 3 of 6 DVM patients with normal responses.

As a positive predictor, our study suggests that the flash VEP does no better than chance $(45.1 \%)$ in predicting a poor prognosis from an initially abnormal VEP. This was the case irrespective of the particular condition which led to CVI. Even though sensitivity was high at $87.5 \%$, it was achieved at the cost of low specificity $(39.3 \%)$. The reasons for the large number of false-positives are several. The flash VEP demonstrates large variability in form, amplitude and latency in the adult normal population, the effects being further exacerbated in the first 6 months of life when there is significant maturational development. $^{3,10.18}$ There is thus some ambiguity in interpreting 'normality' and 'abnormality'. It is therefore probable that at least some cases were classified as having abnormal' VEPs because of limited statistical precision.

In terms of physiological factors, abnormally prolonged maturation of sensory visual pathways, as is presumably possible in idiopathic DVM, could produce an initially abnormal VEP and this may have been the case in our 3 of 6 such patients with this condition. In the meningitis group, even though all 5 had abnormal VEPs only 2 demonstrated no visual improvement, which suggests that there had been significant recovery in function of the visual pathways subsequent to the VEP being performed. In the groups with cerebral malformations and neonatal encephalopathy, the VEP was a much better positive predictor, as out of 13 infants with

Table VI. Infants with neonatal encephalopathy $(n=6)$

\begin{tabular}{ll}
\hline Initial VEP findings & Visual outcome \\
\hline 2 Normal & 1 Impaired \\
& 1 Severely impaired \\
1 Attenuated & Reduced \\
1 Delayed & Impaired \\
1 Attenuated and delayed & Severely impaired \\
1 Absent & Blind \\
\hline
\end{tabular}


abnormal responses, 11 showed no improvement in visual outcome. This observation is at odds with that of Frank and Torres, ${ }^{13}$ who reported that there were no significant differences in the abnormality of flash VEPs from two groups of neurologically handicapped children with and without cerebral blindness, leading them to question the accuracy of VEPs in this condition.

Such variability of findings in studies utilising the flash VEP is possibly not surprising as its efficacy in conveying information on form vision or visual acuity is inferior to the pattern VEP, which correlates well with such measures (for review see Mackie and $\mathrm{McCulloch}^{2}$ ). A normal flash VEP being a gross response indicates little about the spatial and contrast processing functions of those pathways subserving macular vision, and therefore it is quite possible that it may be unaffected when such spatial contrast mechanisms are significantly impaired. However, our finding that the flash VEP is a good negative predictor suggests that it conveys information on the viability of pathways to support subsequent development of form vision/acuity, despite the fact that it does not intrinsically correlate with such function. As to the conclusions which can be drawn from an abnormal flash response, it is highly unlikely that the gross pathway dysfunction it detects would not embrace those of the macula too and, therefore, it is reasonable to suggest that visual acuity/form vision would be severely affected. It is therefore conceded that the pattern VEP will always be a more powerful investigation tool, but in the cases reported herein the children were too poorly to cooperate with such and the flash VEP was all that was practically achievable.

In conclusion, therefore, we would assert that, as evinced by this study where 28 of 44 infants demonstrated significant visual improvement, it is important not to be too pessimistic about visual outcome when faced with an apparently blind child. There are no absolute indicators of prognosis, but the presence of a structural cerebral lesion or a history of neonatal encephalopathy are particularly bad prognostic signs. Apparently blind infants with normal eyes, normal electroretinograms and normal flash VEPs are a subgroup with a relatively good prognosis.

The authors express their thanks to Karen Copeland and Anne Smith for technical and secretarial assistance, respectively.

Key words: Cortical visual impairment, Visual evoked potential.

\section{REFERENCES}

1. Lambert SR, Taylor D, Kriss A. The infant with nystagmus, normal appearing fundi, but an abnormal ERG. Surv Ophthalmol 1989;34:173-86.
2. Mackie R, McCulloch D. Assessment of visual acuity in multiply handicapped children. Br J Ophthalmol 1995; 79:290-6.

3. Mushin J. Visual evoked potentials. In: Levene MI, Bennet MJ, Punt J, editor. Neonatal neurology and neurosurgery. Edinburgh: Churchill Livingstone, 1988: 206-12.

4. Taylor M, McCulloch D. Prognostic value of VEPs in young children with acute onset of cortical blindness. Pediatr Neurol 1991;7:111-5.

5. Wong V. Cortical blindness in children: a study of etiology and prognosis. Pediatr Neurol 1991;7:178-85.

6. Lambert S, Kriss A, Taylor D. Detection of isolated occipital lobe anomalies during early childhood. Dev Med Child Neurol 1990;32:451-5.

7. Muttitt S, Taylor M, Kobayashi J, Macmillan L, Whyte H. Serial visual evoked potential and outcome in term birth asphyxia. Pediatr Neurol 1991;7:86-90.

8. Taylor M, Murphy W, Whyte H. Prognostic reliability of somatosensory and visual evoked potentials of asphyxiated term infants. Dev Med Child Neurol 1992;34:507-15.

9. McCulloch D, Taylor M, Whyte H. Visual evoked potentials and visual prognosis following perinatal asphyxia. Arch Ophthalmol 1991;109:229-33.

10. Lambert S, Kriss A. Electroretinography and visual evoked cortical potential in developmental delay. In: Heckinlively J, Arden G, editors. Principles and practice of clinical electrophysiology of vision. St Louis: Mosby/Year Book, 1991:581-4.

11. Fielder A, Russell-Eggitt I, Dodd K, Mellor D. Delayed visual maturation. Trans Ophthalmol Soc UK 1985;104:653-61.

12. Hoyt C. The clinical usefulness of the visual evoked response. Paediatr Ophthalmol Strabismus 1984;21: 231-4.

13. Frank Y, Torres F. Visual evoked potentials in the evaluation of 'cortical blindness' in children. Ann Neurol 1979;6:126-9.

14. Aldrich M, Alessi A, Beck R, Gilman S. Cortical blindness: etiology, diagnosis, and prognosis. Ann Neurol 1987;21:149-58.

15. Bodis-Wollner I, Atkin A, Raab E. Visual association cortex and vision in man: pattern-evoked occipital potentials in a blind boy. Science 1977;198:629-31.

16. Whiting S, Jan J, Wong P, Farrell OF, McCormick A. Permanent cortical visual impairment in children. Dev Med Child Neurol 1985;27:730-9.

17. Dubowitz L, Mushin J, Vries LD, Arden G. Visual function in the newborn infant: is it cortically mediated? Lancet 1986;I:1139-41.

18. Harding G. Flash visual evoked cortical potential in development delay. In: Heckinlively J, Arden G, editors. Principles and practice of clinical electrophysiology of vision. St Louis: Mosby/Year Book, 1991:585-8.

19. Jasper H. Report to the Committee on Methods of Clinical Examination in Electroencephalography. Electroencephalogr Clin Neurophysiol 1958;10:370-5.

20. Ciganek L. The EEG response (evoked potential) to light stimulus in man. Electroencephalogr Clin Neurophysiol 1961;13:163-72.

21. Denny-Brown D, Chambers RA. Physiological aspects of visual perception. Arch Neurol 1976;33:219-27. 